\title{
The Evolution of Stream Dissolved Organic Matter Composition Following Glacier Retreat in Coastal Watersheds of Southeast Alaska
}

Amy Dehner Holt ( $\sim$ adh19d@my.fsu.edu )

Florida State University https://orcid.org/0000-0001-7091-9416

Jason Fellman

University of Alaska Southeast

Eran Hood

University of Alaska Southeast

Anne M Kellerman

Florida State University

Peter Raymond

Yale University

Aron Stubbins

Northeastern University

Thorsten Dittmar

Institute of Chemistry and Biology of Marine Environment, University of Oldenburg

Robert G.M Spencer

Florida State University

\section{Research Article}

Keywords: deglaciation, dissolved organic carbon, FT-ICR MS, carbon isotopes, succession, Glacier Bay

Posted Date: February 23rd, 2021

DOI: https://doi.org/10.21203/rs.3.rs-237529/v1

License: (1) (1) This work is licensed under a Creative Commons Attribution 4.0 International License.

Read Full License 


\section{Abstract}

Climate change is melting glaciers and altering watershed biogeochemistry across the globe, particularly in regions dominated by mountain glaciers, such as southeast Alaska. Glacier dominated watersheds exhibit distinct dissolved organic matter (DOM) characteristics compared to forested and vegetated watersheds. However, there is a paucity of information on how stream DOM composition changes as glaciers retreat and terrestrial ecosystem succession ensues. Importantly, it is unclear over what timescales these transformations occur. Here, we used bulk, isotopic and ultrahigh resolution molecularlevel techniques to assess how streamwater DOM composition evolves in response to glacier retreat and subsequent terrestrial ecosystem succession. For this, water samples were collected from eleven streams across a chronosequence spanning a temporal gradient 0 to 1,400 years since glacier retreat in coastal, southeast Alaska. During the first 200 years since glacier retreat, stream DOM showed marked and consistent changes in bulk, isotopic, and molecular-level composition. In particular, there was a decreased abundance of ancient, energy-rich (e.g., elevated aliphatic contribution), low aromaticity (e.g., low SUVA 254 and AI mod ) DOM and an increased abundance of soil and vegetation derived aromatic DOM (e.g., more depleted d $13 \mathrm{C}$, elevated condensed aromatic and polyphenolic contribution) that had a modern radiocarbon age. After 200 years of ecosystem development, DOM composition was comparable to that observed for other temperate and arctic forested watersheds without permafrost influence. These results underscore the timelines on which glacier retreat may have substantial impacts on watershed biogeochemistry and coastal ecosystems that receive DOM subsidies from these rapidly changing landscapes.

\section{Full Text}

Due to technical limitations, full-text HTML conversion of this manuscript could not be completed. However, the manuscript can be downloaded and accessed as a PDF.

\section{Figures}



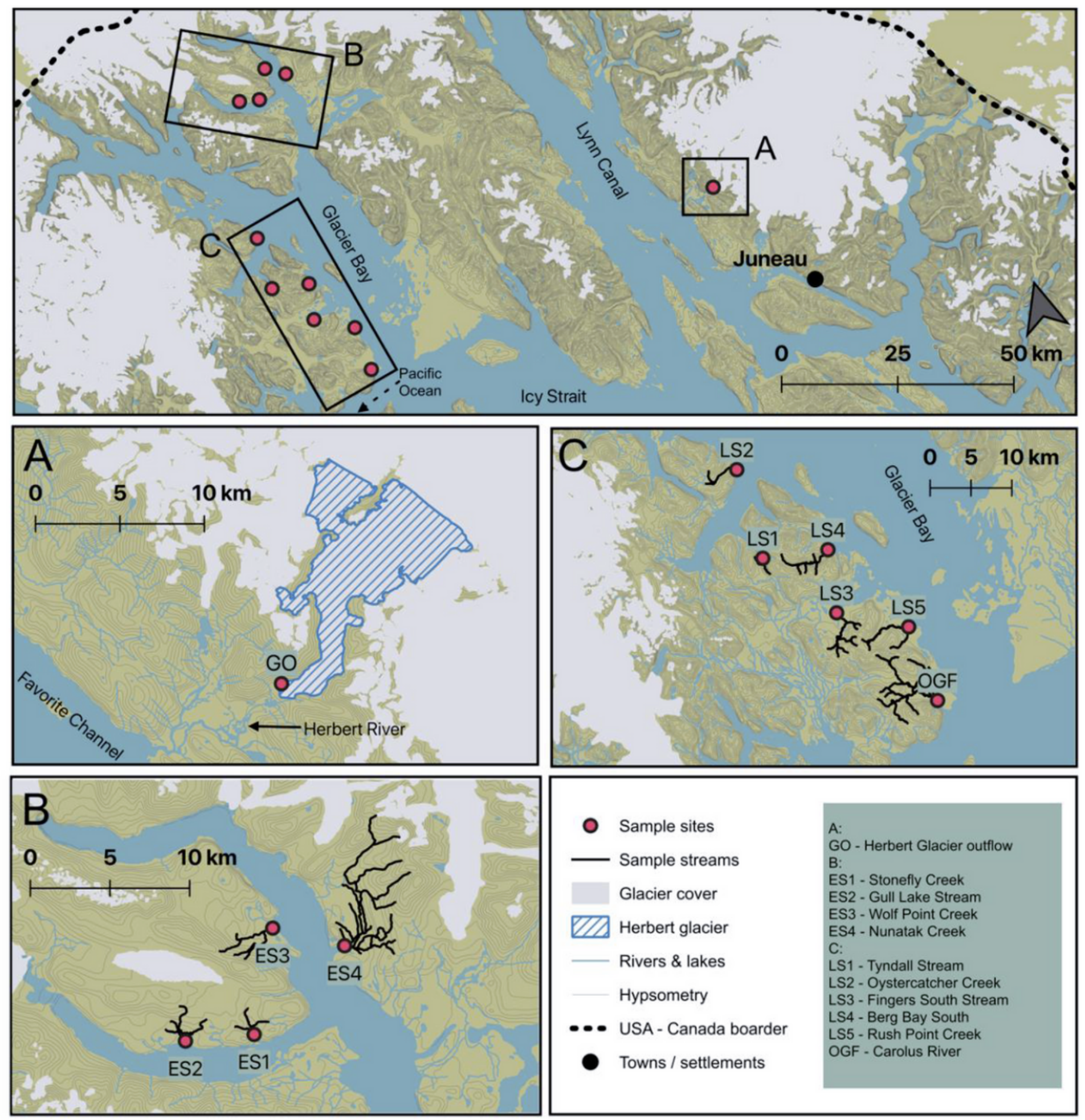

Figure 1

Location of 2013 sample locations in southeast Alaska. (a) Herbert Glacier outflow (GO0), (b) early succession (50 - 100 years) streams (ES50-100) and (c) late succession (>100- 210 years) streams and old growth forest stream (1393 years) in Glacier Bay (LS100-210 and OGF1393, respectively). Map data: glacier cover from Global Land Ice Measurements (GLIMS; http://www.glims.org) and hydrology, land boundaries and hypsometry from Alaskan Department of Natural Resources 
(http://www.asgdc.state.ak.us). Note: The designations employed and the presentation of the material on this map do not imply the expression of any opinion whatsoever on the part of Research Square concerning the legal status of any country, territory, city or area o bbnhir of its authorities, or concerning the delimitation of its frontiers or boundaries. This map has been provided by the authors.

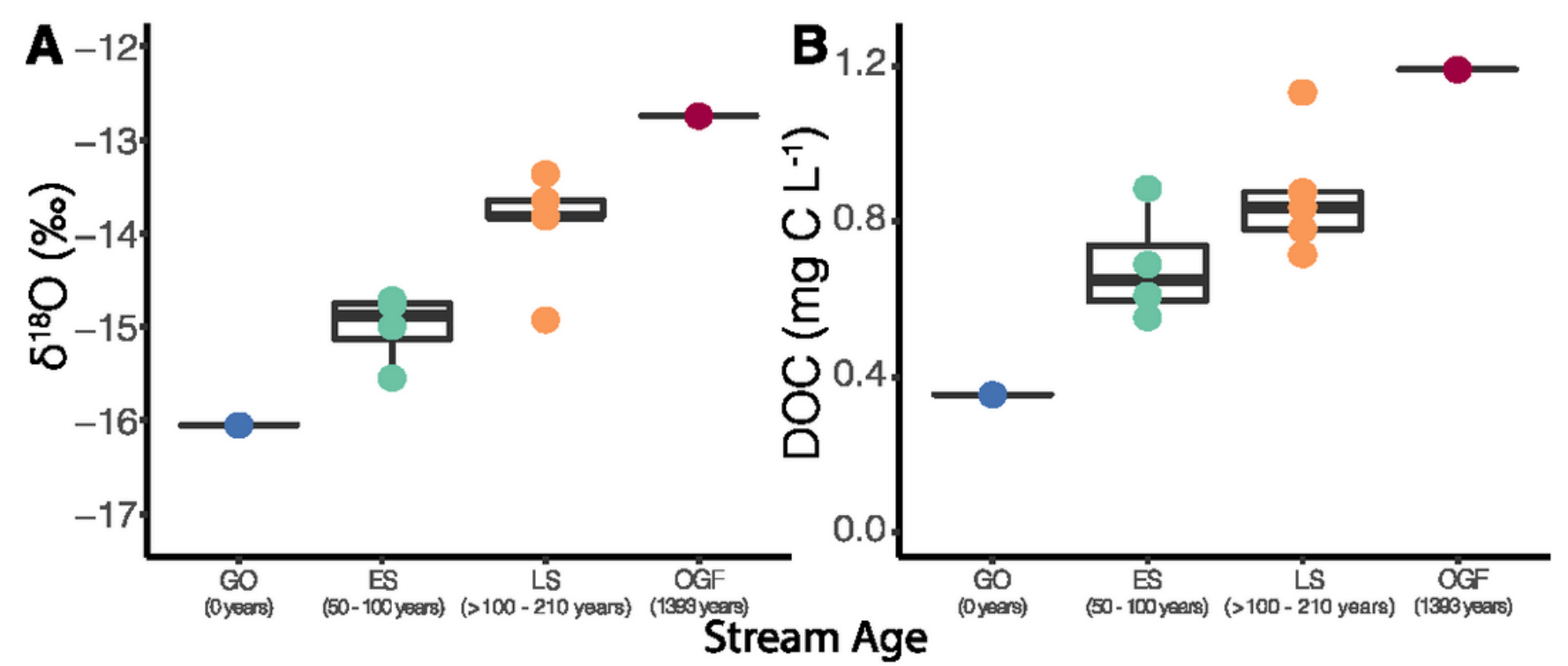

Figure 2

(a) $\mathbb{1 8 0}$ and (b) DOC concentration catagorised by stream age. Dots represent individual datapoints. Herbert Glacier outflow (GO0) and Carolus River old growth forest (OGF1393) streams are a n of one. Early and late succession streams are abrievated to ES50-100 and LS100-210, respectively. 

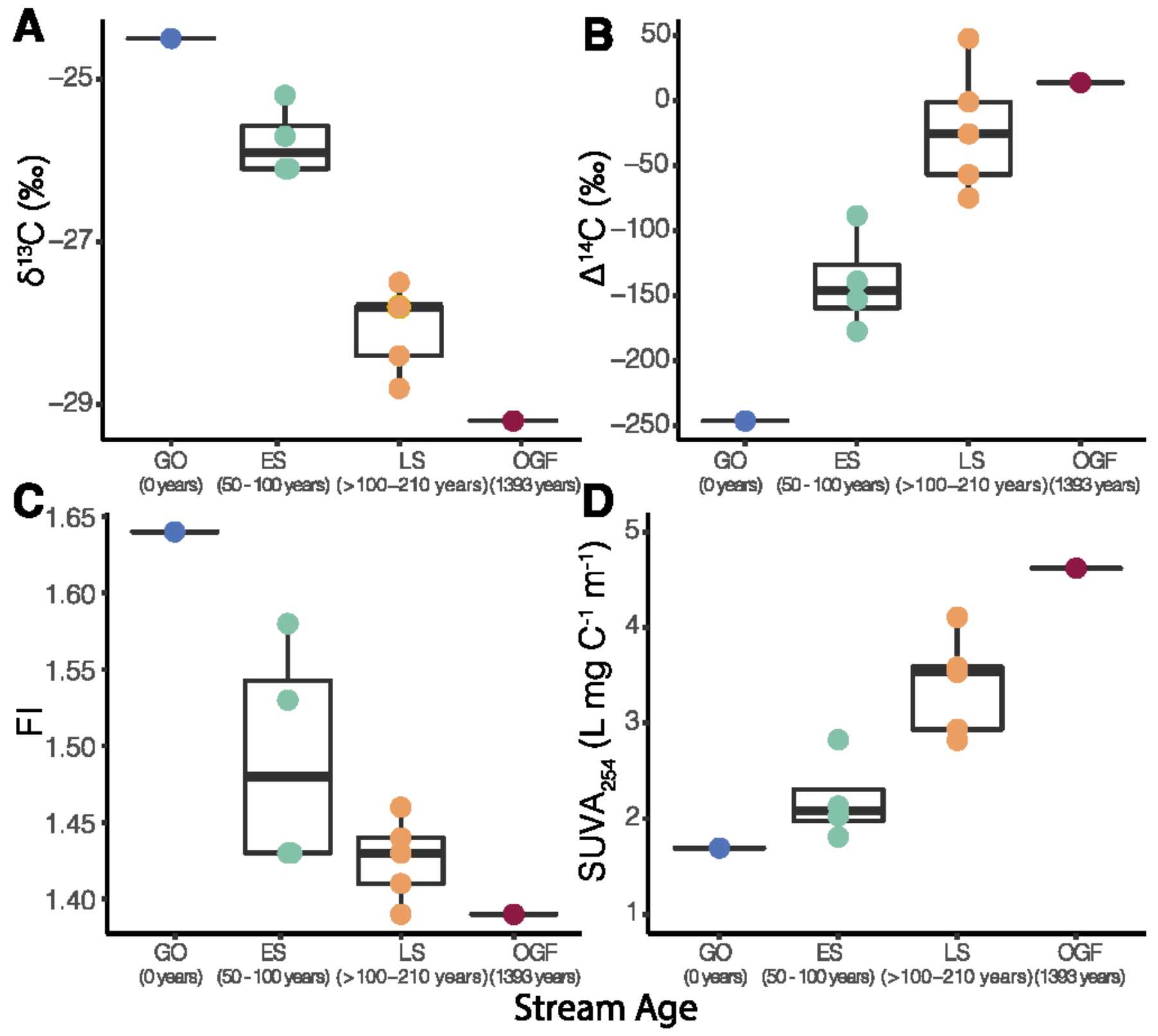

Figure 3

(a) $813 C-D O C$, (b) $\triangle 14 C-D O C$, (c) Fluorescence Index (FI) and (d) SUVA254 catagorised by stream age. Glacier outflow (GO0) and old growth forest (OGF1393) streams are a $\mathrm{n}$ of one. Early and late succession streams are abrievated to ES50-100 and LS100-210, respectively. Dots represent individual datapoints. 


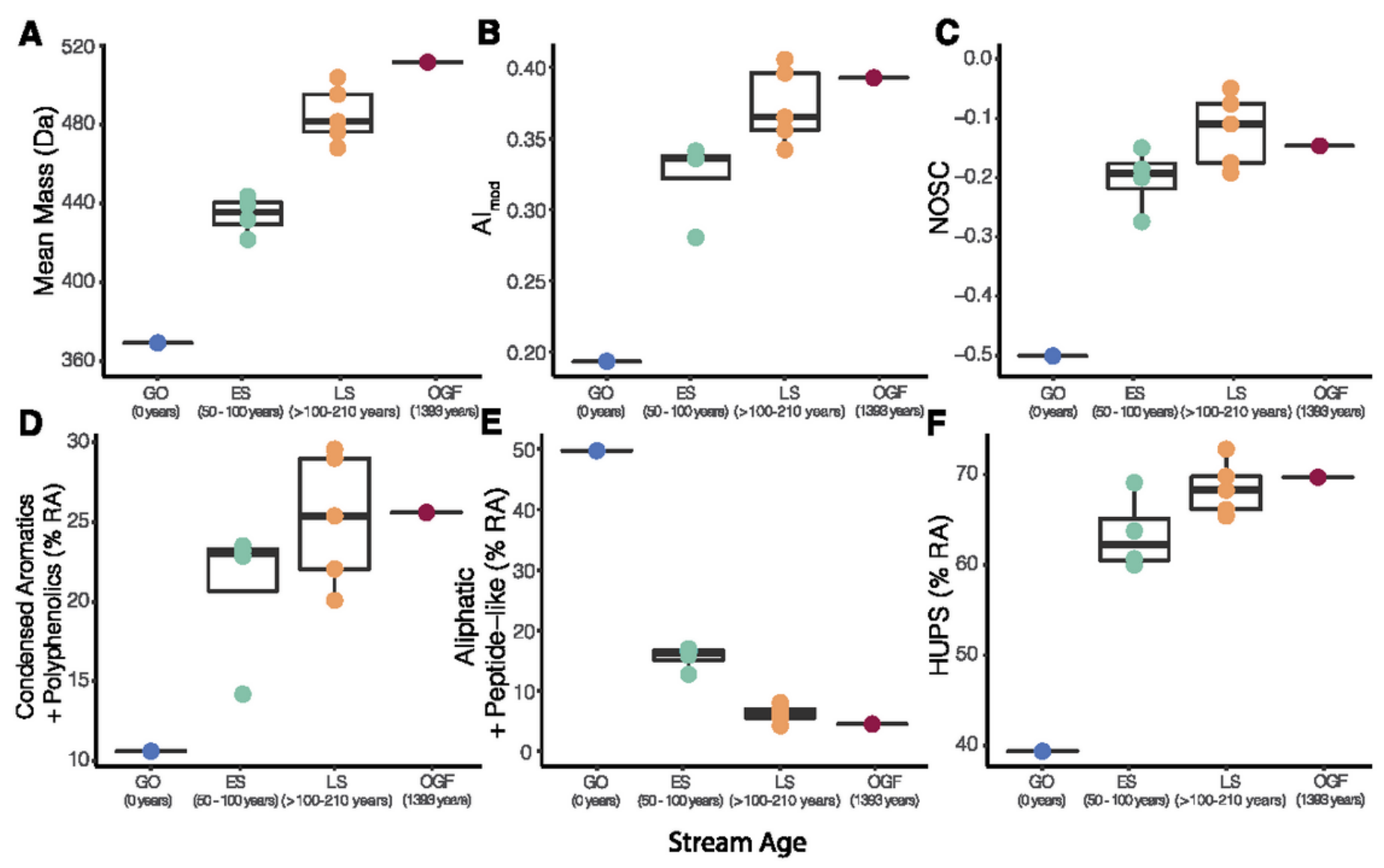

Figure 4

Relative abundance (RA) weighted average mass, Almod and NOSC (a-c), together with compound class scores (d-f) seperated by stream age category. Glacier outflow (GO0) and old growth forest (OGF1393) streams are a n of one. Early and late succession streams are abrievated to ES50-100 and LS100-210, respectively. Dots represent individual datapoints. 


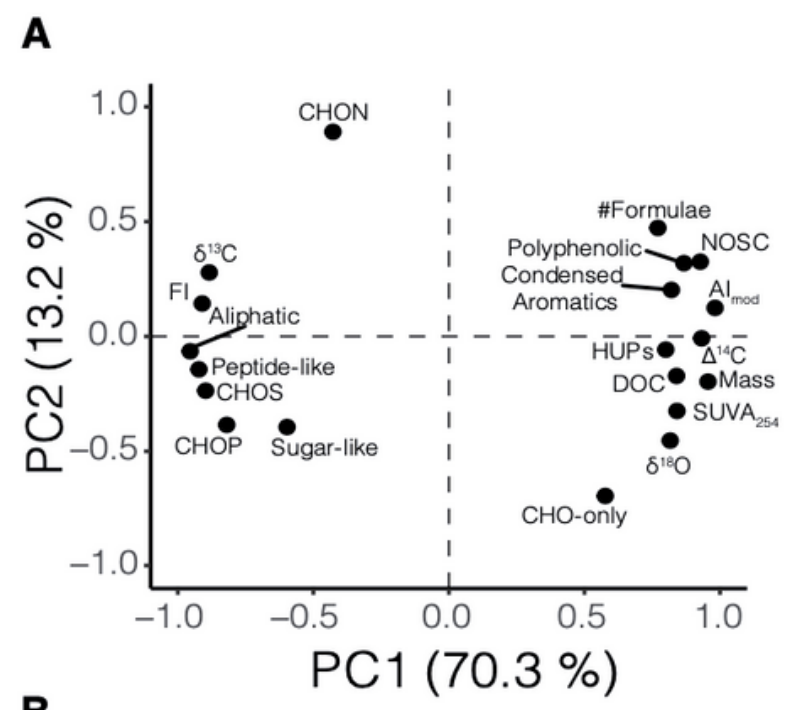

B
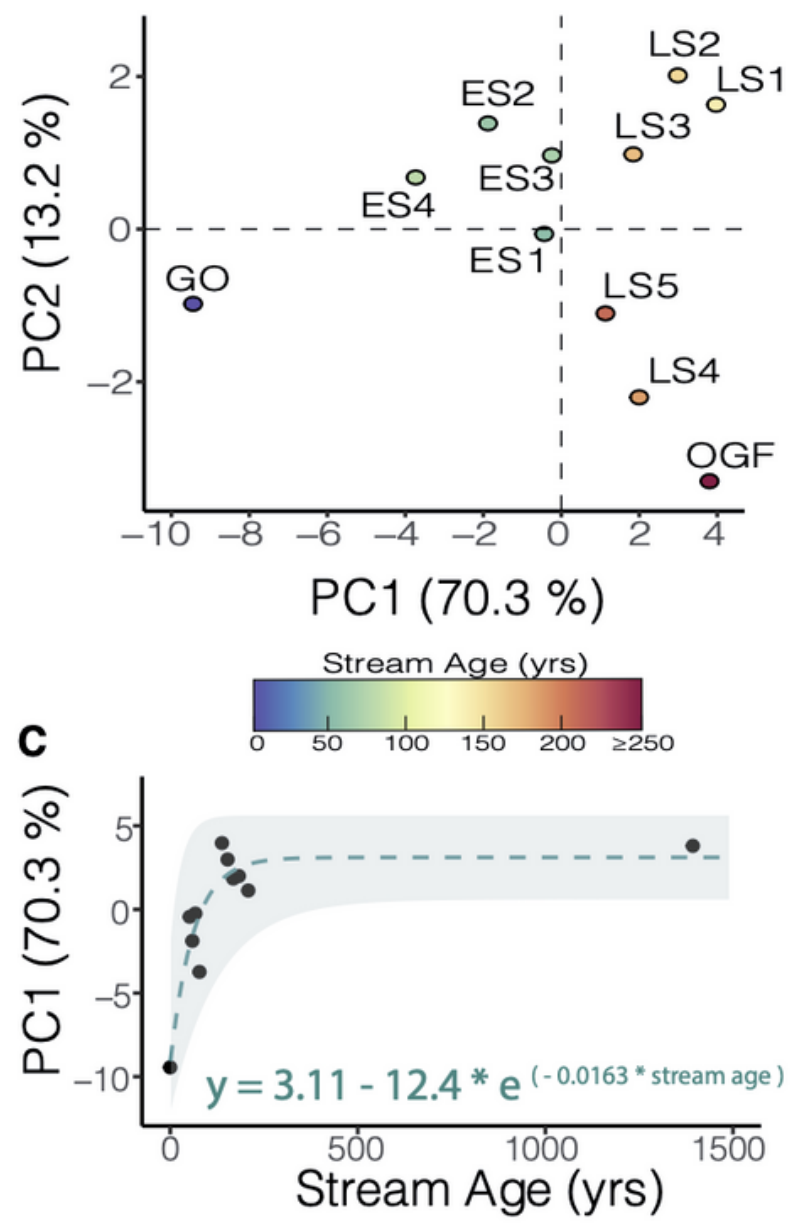

Figure 5

(a \& b) PC analysis for streams based on environmental, bulk-DOC, optical and FT-ICR MS parameters. (b) shading represents stream age, note separation along PC1 by stream age. Stream names are abbreviated (see Figure 1 for full name): GO (Herbert Glacier outflow, 0 years), ES $1-4$ (stream age > $50-100$ years, early succession), LS $1-5$ (stream age $>100-210$ years, late succession) and OGF Carolus River (1393 
years). (c) Asymptotic regression for stream position on PC1 axis with stream age, grey shading represents the $95 \%$ confidence interval of the asymptotic regression parameters.
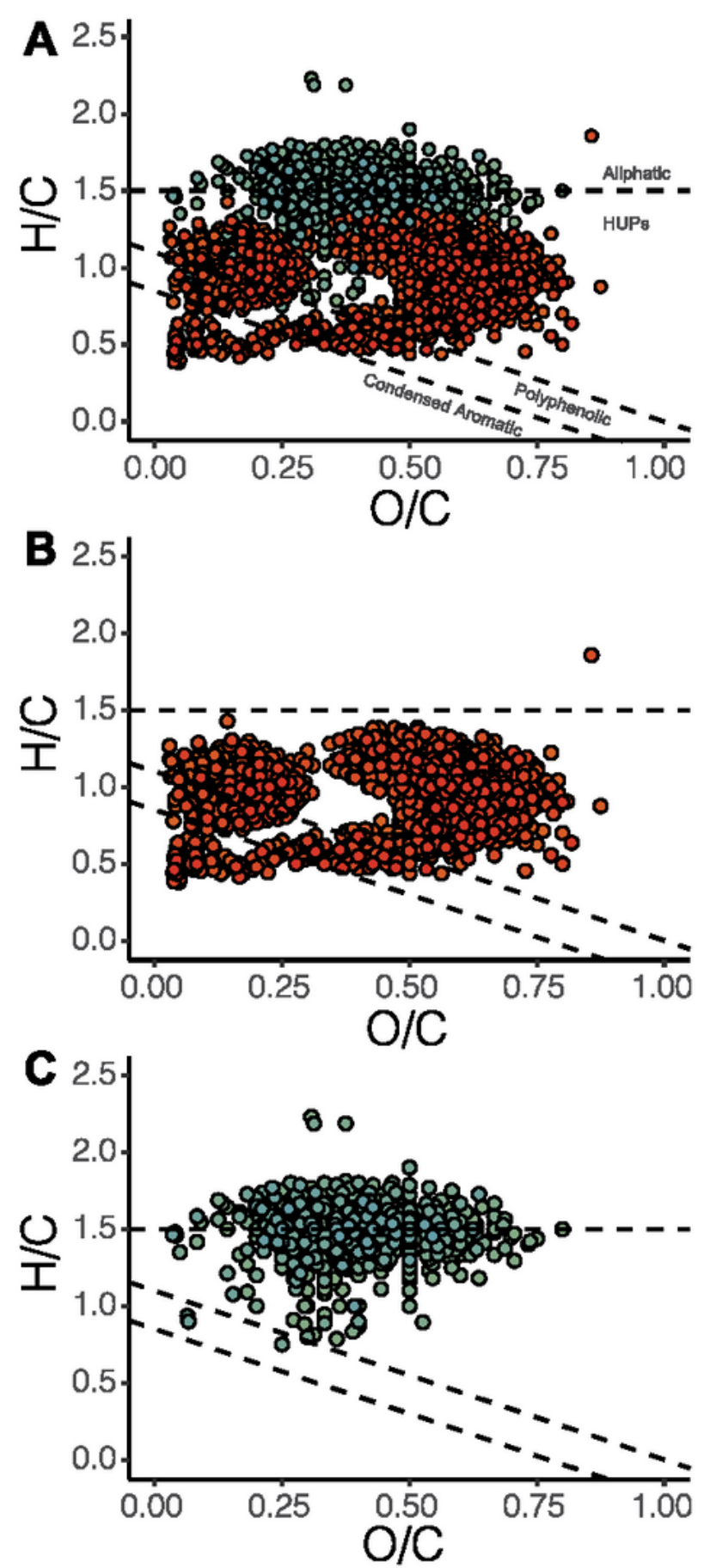

Spearman's Rank Coefficient

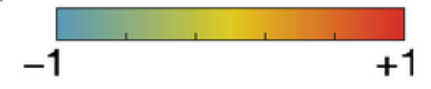

Figure 6

van Krevelen diagrams showing the association between individual molecular formulae and stream age. Only formulae with significant correlations ( $p$-value $<0.05$ ) are plotted. (a) Colouring indicates strength of spearman correlation, where positive (red) represent formulae that increase in relative abundance with 
stream age, blue is the inverse. ( $b$ \& c) Molecular compounds are separated by direction of spearman correlation (positive and negative are $b$ and $c$, respectively). Dashed lines delineate the approximate location of different compounds groups. 